\title{
SOBRE EL APARENTE DÉFICIT DEL DELITO DE ASOCIACIÓN ILÍCITA. UNA PROPUESTA DE RESOLUCIÓN BAJO EL PRISMA HISTÓRICO-LEGISLATIVO
}

\begin{abstract}
ON THE APPARENT DEFICIT OF THE CRIME OF ILLICIT ASSOCIATION. A PROPOSAL FOR RESOLUTION UNDER

THE HISTORICAL-LEGISLATIVE PRISM
\end{abstract}

\begin{tabular}{|c|c|}
\hline \multicolumn{2}{|c|}{ ARTÍCULO INÉDITO DE INVESTIGACIÓN } \\
\hline Cómo CITAR ESTE ARTíCULO (CHICAGO) & 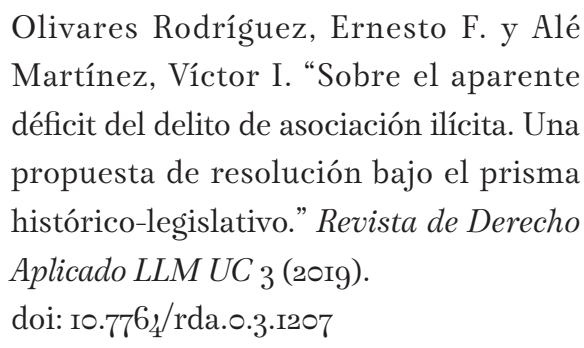 \\
\hline REVISTA DE DERECHO APLICADO LLM UC & $\begin{array}{l}\text { Número } 3 \\
\text { Julio } 2019 \\
\text { ISSN: } 245^{2-4344}\end{array}$ \\
\hline & $\begin{array}{l}\text { Recepción: } 22 \text { de abril, } 20 \text { I9 } \\
\text { Aceptación: } 22 \text { de julio, } 20 \text { I9 }\end{array}$ \\
\hline
\end{tabular}




\section{Resumen}

No obstante tratarse de una figura originaria del Código Penal de 1875, de cierta notoriedad social en algunos momentos determinados de nuestra historia más reciente, lo cierto es que el delito de asociación ilícita de los artículos 292 y siguientes del Código Penal, no ha sido objeto de un tratamiento pormenorizado en la doctrina nacional, con excepción de ciertos trabajos o estudios más bien referidos a aspectos específicos. Por tal motivo, algunos problemas básicos que plantean su interpretación y aplicación suelen ser resueltos empleando al efecto concepciones que, con independencia de su valor, resultan un tanto ajenas a los escasos pero provechosos antecedentes histórico-legislativos del delito. Bajo esta premisa, el presente trabajo tiene por objeto demostrar que, antes de ir tan lejos en la búsqueda de soluciones, puede resultar igualmente útil acudir al "elemento histórico" como medio eficaz de interpretación del delito, teniendo a la vista especialmente el modelo comparado que se tuvo en cuenta en la formulación del tipo penal y las actas de la Comisión Redactora del Código Penal chileno.

Palabras clave: asociación ilícita, asociación organizada, Código Penal Chileno, Código Penal Belga

\section{Abstract}

Despite being an original figure of the Criminal Code of 1875 , of certain social notoriety at certain times in our most recent history, the truth is that the crime of unlawful association of articles 292 and following of the Criminal Code has not been object of a detailed treatment in the national doctrine, with the exception of certain works or studies rather referred to specific aspects. For this reason, some basics problems that arise its interpretation and application are usually solved using the effect conceptions that, regardless of their value, are somewhat alien to the few but useful historical-legislative history of crime. Under this premise, the present work aims to demonstrate that, before going so far in the search for solutions, it may be equally useful to resort to the historical element as an effective means of interpreting crime, especially considering the comparative model that was taken into account in the formulation of the criminal type and the minutes of the Drafting Commission of the Chilean Penal Code.

Keywords: illicit association, organized association, Chilean Criminal Code, Belgian Penal Code 


\section{Ernesto Francisco Olivares Rodríguez}

Olivares Cisternas Abogados

Santiago, Chile

eolivares@ocabogados.cl

Olivares Cisternas Abogados

Santiago, Chile

eolivares@ocabogados.cl
Ernesto Francisco Olivares Rodríguez es abogado de la Pontificia Universidad Católica de Chile. Es Magíster en Derecho Penal de la Universidad de Talca - Universidad Pompeu Fabra y Postítulo en Gestión y Planificación Tributaria de la Universidad Adolfo Ibáñez. Ayudante del Departamento de Derecho Penal, Pontificia Universidad Católica de Chile. Socio de Olivares Cisternas Abogados.

Ernesto Francisco Olivares Rodríguez is a lawyer from Pontificia Universidad Católica de Chile. He holds a Master of Criminal Law from Universidad de Talca - Universidad Pompeu Fabra and Postgraduate degree in Tax Management and Planning from Universidad Adolfo Ibáñez. He is Teaching Assistant at the Department of Criminal Law, Pontificia Universidad Católica de Chile. Partner at Olivares Cisternas Law Firm.

\section{Víctor Ignacio Alé Martínez}

Olivares Cisternas Abogados

Santiago, Chile

vale@ocabogados.cl

Olivares Cisternas Abogados

Santiago, Chile

vale@ocabogados.cl
Víctor Iǵnacio Alé Martínez es abogado de la Universidad de Chile y Diplomado en Derecho Penal Económico y de la Empresa por la misma universidad. Ayudante (ad honorem) del Departamento de Ciencias Penales, Universidad de Chile. Abogado asociado de Olivares Cisternas Abogados.

Víctor Ignacio Alé Martínez is a lawyer from Universidad de Chile and Diploma of Economic and Business Criminal Law, at the same university. He is Teaching Assistant (ad honorem) at the Department of Penal Sciences, Universidad de Chile. Associate Lawyer at Olivares Cisternas Law Firm. 


\section{Introducción}

A diferencia de otros delitos, la asociación ilícita de los artículos 292 y siguientes del Código Penal chileno no ha sido objeto de un estudio integral y pormenorizado. Desde luego, especialmente en el presente siglo, algunos autores han abordado concienzudamente determinados problemas que presenta la interpretación y aplicación de este delito, sirviéndose al afecto, mayoritariamente, de la opinión autorizada de la doctrina comparada ${ }^{1}$. Otro tanto ha hecho la jurisprudencia, realizando una labor que, prima facie, parece ser de carácter creativo-estructural, sobre todo cuando se trata de precisar los elementos del tipo objetivo del injusto, evidenciando, aparentemente, algo así como un cierto déficit en el origen del tipo penal en cuestión.

En este contexto, emprenderemos la tarea de exponer, analizar y demostrar que algunos de los problemas elementales que presenta la configuración de la asociación ilícita pueden ser resueltos por la vía de revisar con cierto detenimiento sus antecedentes histórico-legislativos. En primer lugar, se revisará sucintamente la utilidad del "elemento histórico" de interpretación de la ley penal para efectos de la posterior resolución de ciertos problemas asociados a este delito. En segundo lugar, se hará referencia al modelo legislativo que sirvió de base para la redacción del delito y los motivos de su adopción. Una vez aclarado lo anterior, y en tercer lugar, se analizará y propondrá la resolución de, al menos, cuatro problemas que presenta el delito de asociación ilícita tipificado en el Código Penal chileno: la determinación de los presupuestos típicos objetivos del delito; la finalidad amplia o limitada del programa criminal de la asociación; la cantidad mínima de miembros de una organización delictual; y el problema asociado al concurso que tiene lugar entre este delito y aquellos que forman parte de su agenda delictiva.

\section{Sobre el elemento histórico en la interpretación jurídica}

Es criterio común aquel que plantea la necesidad de interpretación de toda ley, en tanto sólo después de ser objeto de un ejercicio hermenéutico podrá ser aplicada, para así dar cumplimiento a su función de regular la vida social. Resulta pertinente, entonces, la

1 Cf., sobre un estudio global del delito de asociación ilícita, Francisco Grisolía, "El delito de

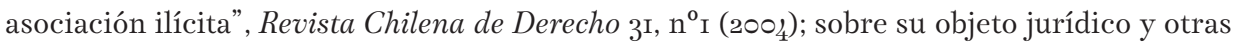
particularidades, José Guzmán Dálbora, “Objeto Jurídico y Accidentes del Delito de Asociaciones Ilícitas”, Estudios y Defensas Penales (Santiago: Lexis Nexis, 2005); sobre aspectos dogmáticos del fenómeno de la criminalidad organizada, Juan Pablo Mañalich, "Organización delictiva. Bases para elaboración dogmática en el derecho penal chileno”, Revista Chilena de Derecho 38 $\mathrm{n}^{\mathrm{o}} 2$ (20II): 294-295; sobre el bien jurídico protegido, Gonzalo Medina, "El injusto de la asociación ilícita como problema de la estructura de afectación del bien jurídico", La Ciencia Penal en la Universidad de Chile (Santiago: Facultad de Derecho de la Universidad de Chile, 20I3). 
aseveración de que la interpretación no es un fin en sí mismo, sino un instrumento de aplicación para los casos concretos².

En términos generales, la interpretación de la ley penal es una actividad auxiliar cognoscitiva, consistente en el conjunto de operaciones intelectuales encauzadas a la comprensión del significado de las normas que se pretenden aplicar ${ }^{3}$. En particular, en lo que nos interesa y conforme a nuestro ordenamiento, para efectos de la interpretación jurídica se suele hacer mención a las cuatro conocidas reglas de interpretación que entregan los artículos 19 a 24 del Código Civil chileno ${ }^{4}$, cuya aplicación viene a ser de carácter general, incluyendo, por tanto, las normas jurídico-penales ${ }^{5}$. Desde luego, estas reglas o elementos no resultan excluyentes entre sí, sino que son «cuatro operaciones distintas, cuya reunión es indispensable para interpretar la ley, por más que algunos de estos elementos puedan tener más importancia y hacerse más de notar» ${ }^{6}$.

En relación al método que orienta este trabajo, cabe puntualizar que el "elemento histórico” es un recurso hermenéutico para determinar el sentido de la ley consistente en atribuirle significado a una disposición legal del presente con datos del pasado ${ }^{7}$. Así, lo que se ha denominado "historia fidedigna de la ley", la conforman «los antecedentes que motivaron su dictación, las condiciones socioculturales de la época, cómo se promovió su dictación, los trabajos preparatorios, su mensaje o exposición de los motivos, las discusiones a que dio lugar, las opiniones de sus redactores, el derecho comparado que se tuvo en cuenta, etc.» ${ }^{8}$. Con todo, se ha sostenido que este elemento no tiene generalmente un

2 Manuel Vidaurri, "La interpretación de la Ley Penal”, AA.VV., Liber Ad Honorem Sergio García Ramírez, Tomo I (Universidad Nacional Autónoma de México, Instituto de Investigaciones Jurídicas, Serie E; Varios, Nº 94, I998), 73-732. En Chile, por todos, Enrique Cury, Derecho Penal Parte General (Santiago: Ediciones UC, 2009), I85.

3 Giovanni Fiandaca y Enzo Musco, Derecho Penal, Parte General (Bogotá: Editorial Temis S.A., 2006), , 28.

4 A saber: (i) elemento gramatical [artículo I9, inc.I ${ }^{\circ}$ del Código Civil]; (ii) elemento lógico [artículo I9, inc. $2^{\circ}$ y artículo 22 , inc. ${ }^{\circ}$ del Código Civil]; (iii) elemento histórico [artículo I9, inc. $2^{\circ}$ del Código Civil] y (iv) elemento sistemático [artículo 22, inciso $2^{\circ}$ del Código Civil].

5 Cf., Cury, Derecho Penal...: rgo, Alfredo Etcheberry, Derecho Penal Parte General, Tomo I, $3^{\mathrm{a}}$ Ed. (Santiago: Editorial Jurídica de Chile, I999), 99; Eduardo Novoa, Curso de Derecho Penal Chileno, Parte General, Tomo I, (Santiago: $3^{\text {a }}$ Edición, Editorial Jurídica, 2005), I34.

6 Fiedrich Karl Von Savigny, Sistema del Derecho Romano Actual, Tomo Primero, $2^{\text {a }}$ Ed. (Madrid: Centro Editorial de Góngora, I839-1847), I88.

7 Joaquín Rodríguez-Toubes, "El criterio histórico en la interpretación jurídica”, Dereito 22, nº 599-632 (Noviembre, 2013): 600 .

8 Mario Garrido Montt, Derecho Penal Parte General, Tomo I, $2^{\mathrm{a}}$ Ed. (Santiago: Editorial Jurídica de Chile, 2007), I02. En igual sentido Etcheberry, Derecho Penal..., I05-ıо6. 
carácter decisivo ${ }^{9}$ Y ciertamente lleva razón esa afirmación. Sin embargo, su relevancia "práctica" como herramienta hermenéutica es manifiesta, siendo uno de los mecanismos que más contribuyen a aclarar el contenido de la ley ${ }^{10}$, especialmente a falta de una consolidada elaboración doctrinal ${ }^{11}$. En este sentido, cabe consignar que acudir al momento histórico en que se legisló puede ayudar a desvelar el auténtico sentido y finalidad de la ley. Prueba de ello la encontramos en el estudio realizado por Andreucci Aguilera, en que se analiza la jurisprudencia de cien años de la Corte Suprema, concluyendo lo siguiente:

Vale destacar que este elemento histórico es el más recurrido por los abogados, ya sea en las demandas o en las contestaciones, respecto de las cuales hemos estudiado las sentencias de los recursos de casación en el fondo para elaborar esta tesis. Por lo demás en la inmensa mayoría de las sentencias, la Corte Suprema hace permanente referencia al elemento, ya sea para reforzar su resolución en torno a ese elemento gramatical, o como principal criterio para resolver el asunto que se encuentra en sus manos. Asimismo, la mayoría de los fallos del Tribunal Constitucional, que no son objeto de estudio en esta tesis, utilizan como principal argumento para sentenciar el elemento histórico ${ }^{12}$.

Ciertamente, a través del elemento histórico no se debe desentrañar la voluntad de los legisladores, sino la "voluntad de la ley" ${ }^{13}$. En tal sentido, se ha afirmado que valerse de este criterio hermenéutico no significa que el intérprete tenga un interés puramente filológico o histórico-reconstructivista ${ }^{14}$. En efecto, nuestro propósito no radica únicamente en constatar y fijar axiomáticamente el pensamiento de los redactores al momento de elaborar la normativa penal de la asociación ilícita como un "dato psicológico". Antes bien, a partir de la identificación de ciertas problemáticas asociadas a dicha figura, se busca dar cuenta y destacar que en el proceso objetivado de deliberación legislativa se generaron importantes aclaraciones, opiniones y argumentaciones cuyo correcto entendimiento y análisis permite dar solución y/o encontrar respuestas a tales problemas, cuya incidencia en la práctica, en la elaboración de acciones o defensas, puede ser relevante, especialmente al considerar lo que han señalado algunos autores en cuanto a la disposición del tribunal

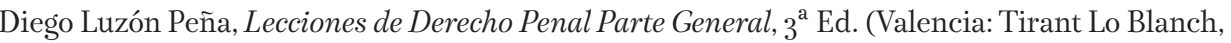
20I6), cap. 6, párrafo I6.

10 Sebastián Soler, Derecho Penal Argentino, Tomo I (Buenos Aires: Tipográfica Editora Argentina, Io ${ }^{a}$ Ed. I992), i 86.

11 Fiandaca y Musco, Derecho Penal..., $\mathrm{I} 36$.

12 Rodrigo Andreucci Aguilera, "Los conceptos de la Corte Suprema sobre interpretación de la ley a través de sus sentencias", Nomos, $\mathrm{n}^{\circ}$ I (2008): 30 .

13 Etcheberry, Derecho Penal..., ro5-ro6, cf. Novoa, Curso de Derecho Penal.., I32.

14 Fiandaca y Musco, Derecho Penal..., I33. 
en relación a este elemento, esto es, que el juez está vinculado a la decisión valorativa político-jurídica del legislador histórico ${ }^{15}$.

\section{La influencia del Código Penal belga en la redacción de los artículos 292 y siguientes del Código Penal}

Ante los frustrados intentos de crear un Código Penal propio, el Gobierno encargó, por Decreto del año 1856, al Ministro de Chile en Bélgica, don Manuel Carvallo, la elaboración de un Proyecto de Código Penal, que posteriormente se denominó Proyecto de Carvallo. En concreto, esta iniciativa constaba de 555 artículos, distribuidos en dos libros, publicándose la Parte General el año 1856, y, juntamente con la Parte Especial, el año $1859^{16}$. Si bien se ha sostenido que el encargo no pudo ser concluido del todo y plasmado en un código definitivo por el fallecimiento del creador del proyecto ${ }^{17}$, cabe destacar que don Manuel Carvallo realizó un trabajo de suma importancia e influencia para el futuro Código Penal chileno, pues también por orden del Gobierno, tradujo al castellano el Código Penal belga, publicándose esta versión el año 1868 en Santiago, por la Imprenta Nacional, en un volumen de 208 páginas $^{18}$. La influencia de este último cuerpo normativo sería decisiva para ciertos articulados del Código Penal chileno, entre ellos los referidos a la asociación ilícita.

Algunos años después, específicamente el 17 de enero de 1870, se constituyó por decreto supremo una Comisión encargada de redactar y elaborar un Código Penal propio ${ }^{19}$. En la

15 Claus Roxin, Derecho Penal Parte General, Tomo I., $2^{\text {a }}$ edición alemana (España: Editorial Civitas, 2008), $\mathrm{I} 5^{\circ}$.

16 Novoa, Curso de Derecho Penal...,I०3; Jean Pierre Matus, "La doctrina penal de la (fallida) recodificación chilena del siglo XX y principios del XXI”, Polít.Crim. 5, nº 9 (20I0): I5I.

17 Jean Pierre Matus sugiere que esta no puede ser la verdadera razón por la cual el proyecto de código no fue terminado, ya que la muerte de don Manuel Carvallo se produjo en I867 (Jean Pierre Matus, "La doctrina“, I5). Con esto, el autor abandona la hipótesis planteada con anterioridad en su manual de Derecho Penal Parte General (2004), donde sostenía que la muerte de Carvallo era la única razón por la cual se abandonó el proyecto. Cf. Sergio Politoff, Jean Pierre Matus, Cecilia Ramírez, Lecciones de Derecho Penal Chileno. Parte General (Santiago: Editorial Jurídica de Chile, 2004), 29.

18 Emilia Iñesta Pastor, "El Código Penal Chileno de I874", Revista Chilena de Historia del Derecho, n ${ }^{0}$ I9 (2003-2004): 302 .

19 En un principio fue presidida por don Alejandro Reyes y compuesta por don Pedro Eulogio Altamirano, don José Clemente Fabres, don José Vicente Abalos, don Diego Armstrong, don José Antonio Gandarillas y don Manuel Rengifo. Con posterioridad, se integró a la Comisión don Adolfo Ibáñez, en reemplazo de don José Vicente Abalos. Al respecto, cf. Sergio Politoff, Jean Pierre Matus y Cecilia Ramírez, Lecciones de Derecho Penal..., 29; Luis Mac Iver, Derecho Penal Chile. Parte General. Tomo I (Santiago: Editorial Jurídica de Chile, 1975), 75. 
sesión preparatoria de 8 de marzo de 1870, se abrió un arduo debate entre los miembros de la Comisión Redactora en orden a determinar el modelo de inspiración de nuestra nueva legislación penal. Al respecto, el Ministro de Justicia de la época y Presidente de la Comisión, don Joaquín Blest Gana, sostuvo que el Código Penal belga, en virtud de su precisión, claridad y sencillez, era superior a cualquier otro cuerpo normativo de referencia, para servir de base en la reforma de la legislación penal chilena en aquella época ${ }^{20}$.

Ante la oposición del comisionado don Alejandro Reyes, quien era de la opinión favorable al Código Penal español -sobre la consideración de tener una división más lógica que el cuerpo normativo belga y, además, por la cercanía cultural con el pueblo español ${ }^{21}$-, se suscitó un debate que se iba a resolver, según consta en las actas, únicamente en la sesión del 1 de abril de 1870.

En definitiva, la sesión $2^{\text {a }}$ tuvo lugar el día 26 de abril del mismo año, y sería la última vez que presidiría don Joaquín Blest Gana, tal vez augurando que su proposición inicial de adoptar el modelo belga no sería aprobada por los demás comisionados. En lo que interesa, el comisionado don Alejandro Reyes manifestó:

Que tanto por nuestras costumbres, mas en relación con las del pueblo español que con las del belga, como por ser mas completo, debía adoptarse el Código español como punto de partida para los debates. No siendo pequeña razon para esta preferencia tambien, la de tener un comentador como el señor Pacheco, cuyos estudios se hallaban concordados a la vez con las disposiciones de seis códigos distintos, que servirían inmensamente para ilustrar la materia ${ }^{22}$.

Con todo, es importante advertir que lo acordado por los comisionados era que el modelo español serviría de punto de partida para los debates, por lo que en algunos preceptos se podría seguir un criterio y redacción distinta, cual es el caso de los artículos 292 y ss., del Código Penal chileno ${ }^{23}$.

En lo que respecta al delito de asociación ilícita, fue en la sesión $62^{\mathrm{a}}$, de 16 de octubre de 1871, donde se adoptó la decisión de tomar como modelos del ilícito los artículos 322 a 326

22 Rivacoba, Código Penal..., 248. Cabe agregar que varios miembros de la Comisión consideraron que "a pesar de su fecha, el Código Belga, como simple revisión del francés que es, resulta incomparablemente más antiguo y menos evolucionado que el español”, lo cual sirvió de fundamento para el apoyo definitivo a la propuesta del comisionado Sr. Reyes (Rivacoba, Código Penal..., 46).

23 Es la situación también, entre otros, del actual artículo I5 $\mathrm{N}^{\circ}$ 2, parte segunda, del Código Penal, con el amplio significado de la voz "inducir". Según quedó consignado en la sesión 1o ${ }^{\mathrm{a}}$, de 24 de mayo de 1870 , su sentido se habría tomado del artículo 66, inciso ${ }_{4}^{\circ}$, del Código Penal belga, que consideraba autores a "los que por dones, promesas, maquinaciones o artificios culpables, hubieren provocado o inducido directamente a la perpetración del delito o falta”. 
del Código Penal belga, quedando en las actas, como artículos provisorios, los números 284, 285, 286 y 287, correlativamente. Es de notar que en esta sesión, presidida por don Alejandro Reyes, no estuvieron presentes todos los comisionados, asistiendo únicamente don Pedro Altamirano, don José Clemente Fábres y don Manuel Rengifo. Resulta particularmente importante esta circunstancia, por razones que más adelante se advertirán con mayor nitidez, aunque podemos adelantar que es justamente esta escasa asistencia la que explicará las ulteriores modificaciones y precisiones al articulado original propuestas en la sesión $157^{\mathrm{a}}$, por el comisionado, don José Antonio Gandarillas, quien al no estar presente en el primer debate de octubre de 1871, efectuó con posterioridad ciertos comentarios y alcances fundamentales -aunque no necesarios, como explicaremos-, para la comprensión del delito.

\section{El Código Penal Chileno}

Finalmente, tras algunas correcciones de orden formal -aunque de influencia sustantiva-, el delito de asociación ilícita quedó regulado y sistematizado en los artículos 292 y ss., del Código Penal, dentro del Título VI, "De los crímenes y simples delitos contra el orden y la seguridad públicos cometidos por particulares", parágrafo 10, "De las asociaciones ilícitas". Como se ha expuesto, se trata de una normativa adoptada del Código Penal belga de 1863, artículos 322 a 326, y más remotamente de la asociación de malhechores del Código Penal francés de 1810 (reformado en 1832 y 1834), artículos 265 a $268^{24}$.

En principio, este Título VI sólo contemplaba los artículos 292, 293, 294 y 295. Los artículos 294 bis y 295 bis fueron agregados por los números 3 y 5 del artículo $1^{\circ}$ del Decreto Ley $\mathrm{N}^{\mathrm{o}} 2.621$, de 28 de abril de 1979, respectivamente.

\section{Algunos problemas planteados en la configuración del delito de asociación ilícita y su resolución conforme a los antecedentes histórico-legislativos}

\section{I. El artículo 292 del Código Penal y la tarea de determinar los presupuestos típicos objetivos del delito}

Es opinión generalizada aquella que atribuye a la doctrina y jurisprudencia -ante la supuesta insuficiencia del artículo 292 del Código Penal- haber "establecido" los requisitos

24 El artículo 265 del Código Punitivo Napoleónico, en su Sección V, "Asociaciones de Malhechores, Vagancia y Mendicidad”, parágrafo § I, "Asociaciones de malhechores" (Association de Malfaiteurs², disponía lo siguiente: "Toda asociación de malhechores, contra las personas ó las propiedades, es un crimen contra la paz pública”. Por su parte, el artículo 266 del referido código complementaba: "Este crimen existe por el solo hecho de la organización de las gavillas, correspondencia, entre ellas y sus gefes ó comandantes, ó de convenciones que tiendan á dar cuenta ó á hacer distribución ó división del producto de sus maldades”. Al respecto, cf., Manuel Zavala, José Ignacio Serrano y Prudencio Meiquia, trads., Código Penal Francés traducido, (México: I866), 59. 
esenciales para entender por configurado el delito de asociación ilícita, al menos en lo que se refiere a los presupuestos objetivos que dan cuenta de la existencia de una estructura organizada con un programa criminal específico. En tal sentido, en la doctrina más antigua se sostenía casi a modo revelador que «la lei no castiga aquí las simples conspiraciones ni las reuniones de hombres que no constituyan cuerpos organizados con sus jefes y reglas propias» ${ }^{25}$. Por su parte, los Tribunales han seguido un camino similar, como lo ilustra la siguiente sentencia:

Es menester que concurran los requisitos que la doctrina y la jurisprudencia señalan, a saber: participación concertada de varias personas, esto es, pluralidad o multiplicidad de individuos; jerarquía que se manifiesta dentro de una organización que evidencia estructura en su funcionamiento, o sea, alguno de sus miembros deben ejercer funciones de mando y otros acatar órdenes e instrucciones, y debe existir cierto grado de organización, lo que significa que cada uno debe cumplir funciones o tareas específicas, dependientes una de otra, para cumplir el o los fines colectivos e instrumentales a los de la agrupación; estabilidad y permanencia en el tiempo; objeto común y preciso de los miembros, ergo, la finalidad de la organización criminal debe ser la comisión de crímenes o simples delitos; convergencia de voluntades en el sentido que el dolo de los integrantes debe ser común al de todos los miembros, considerando el objetivo criminal que tienen y las tareas específicas que a cada cual le corresponde; y medios y recursos para llevar a cabo sus fines delictivos, los que deben ser adecuados a aquellos para los cuales la asociación fue creada ${ }^{26}$.

25 Alejandro Fuensalida, Concordancias i comentarios del Código Penal Chileno, Tomo II (Lima: Imp. Comercial Calle del Huallaca N.r39, I883), 308-314. Más modernamente, Juan Pablo Mañalich ha sostenido que, de lege lata, la estructura de la organización "ha de mostrar suficiente "densidad", tanto en cuanto a su proyección temporal como en cuanto a su complejidad interna: número de miembros, distribución de funciones, etc.”, destacando además la conexión que existe entre asociarse y organizarse (Mañalich, "Organización delictiva”, 294-295). Sobre esto último, cabe señalar que el correcto entendimiento respecto de la diferenciación y, a su vez, íntima y esencial vinculación entre ambos términos (asociación y organización) es lo que constituye concretamente la piedra angular del delito. La “asociación”, por sí sola, no logra aportar suficientemente a la comprensión del injusto, salvo en lo que dice relación con una agrupación de personas en torno a un fin común. Es necesario que esta asociación se encuentre "organizada", de lo que se deriva la estructuración jerárquica, funcional y normativa de que dan cuenta las actas de la Comisión Redactora y las numerosas sentencias de nuestros Tribunales (por vía ejemplar, las sentencias de la Excma. Corte Suprema, rol I.I83-2002, 5·576-2007, 5.8992008, 7.712-2008, 2.747-2009, I4.312-2016).

26 Sentencia de la Excma. Corte Suprema rol 37.965-20I5, considerando décimo. En similar sentido se pronuncia el máximo Tribunal en las sentencias indicadas en pie de página $n^{\circ}{ }_{25}$. A mayor abundamiento, suele ser citada para efectos de ejemplificar los presupuestos típicos del delito, 
Sin perjuicio del valor que ha tenido la opinión constante de la dogmática y de los tribunales al respecto, lo cierto es que una revisión de las actas de la Comisión Redactora del Código Penal permite sostener razonablemente que la doctrina y la jurisprudencia no han "establecido" presupuestos típicos para la configuración del delito de asociación ilícita, sino más bien se han limitado a "precisar" aquellos que ya se contenían en el articulado original del ilícito.

En efecto, el artículo 292 del Código Penal chileno fue recogido del artículo 322 del Código Penal belga, que disponía lo siguiente: «Toda asociación formada con el objeto de atentar contra las personas o las propiedades es un crímen o un delito, que existe por el solo hecho de la organizacion de la partida» ${ }^{27}$.

En la redacción de nuestro Código Penal, el modelo belga sufrió algunas modificaciones que se mantienen en la actualidad. Así, el referido artículo 292 preceptúa: «Toda asociacion formada con el objeto de atentar contra el orden social, contra las buenas costumbres, contra las personas o las propiedades, importa un delito que existe por el solo hecho de organizarse».

Sin perjuicio de algunas diferencias gramaticales, una de las más relevantes es aquella que se gestó en la sesión $157^{\mathrm{a}}$, de 18 de junio de 1873, oportunidad en la cual el comisionado, don José Antonio Gandarillas -ausente en la sesión $62^{\mathrm{a}}$-, pidió que fuera suprimida la palabra "partida" con que finalizaba el artículo en cuestión:

Porque la mente de este artículo es castigar los cuerpos formados para propender a un fin ilícito, de un modo más o menos estable, a diferencia de las conspiraciones para cometer uno o más delitos determinados [...] No basta, por consiguiente, que se forme una partida de criminales para que tenga aplicación el art. 395, es necesario ademas que esa partida constituya un cuerpo organizado con sus jefes i reglas propias ${ }^{28}$.

De la argumentación del comisionado, aprobada por el resto de la Comisión, se advierte que la opinión doctrinal y judicial, antigua y reciente, referida a los elementos objetivos de la organización delictiva, no difiere sustancialmente de lo discutido al interior de la

la histórica sentencia pronunciada por la Iltma. Corte de Apelaciones de Valdivia, en el caso referido a la asociación de brujos indígenas llamada "Recta Provincia". Cf. Alfredo Etcheberry, El

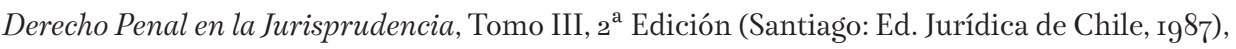
453. De igual tenor son las sentencias citadas por Sergio Politoff, Jean Pierre Matus y María Cecilia Ramírez, Lecciones de Derecho Penal..., 5 ${ }^{\circ}$

27 Mario Verdugo, Código Penal: concordancias, antecedentes históricos, doctrina y jurisprudencia. Tomo II (Santiago: Editorial Jurídica Ediard-Conosur I986), 639.

28 Rivacoba, Código Penal..., $5^{28 .}$ 
Comisión Redactora del Código Penal en la segunda mitad del siglo XIX. El concierto de personas, la jerarquía funcional y normativa, la existencia de un programa criminal y la convergencia de voluntades encuentran su antecedente en este preciso alcance del comisionado Sr. Gandarillas. En consecuencia, no adolece de déficit alguno el tipo penal descrito en el artículo 292 del Código Penal; menos aún, como han pretendido sostener algunos, su redacción infringiría el principio de legalidad ${ }^{29} \mathrm{o}$ el mandato de determinación ${ }^{30}$.

En suma, la asociación debe estar organizada estructural y normativamente en torno a un objetivo criminal específico; premisa básica que ha de ser complementada con el artículo 293 del Código Penal para efectos de determinar la sanción en consideración al grado de intervención individual en la estructura y el propósito delictual perseguido, que únicamente excluye las faltas.

Con todo, cabe hacer una precisión. Si bien la opinión y argumentación del comisionado Sr. Gandarillas ha resultado fundamental para entender el sentido y alcance del injusto, lo cierto es que su comentario más bien se limitó a confirmar lo que el articulado en general del modelo belga ya suponía. Esto es así, pues el modelo que tuvo a la vista la Comisión Redactora contenía una redacción que, analizada sistemática y coherentemente, atribuía

29 Ante el H. Tribunal Constitucional se ha denunciado la inaplicabilidad por inconstitucionalidad de los artículos 292 y 293 del Código Penal, por infringir el principio de legalidad, lo que se evidenciaría por la redacción del primero de los artículos mencionados, en cuanto sanciona el delito por el solo hecho de haberse organizado la asociación. Sin embargo, el H. Tribunal ha desestimado esta alegación por considerar que el delito de asociación ilícita es de "peligro abstracto" y, en ese entendido, "el cuestionamiento irrestricto de los delitos de peligro abstracto puede invalidar la norma que sanciona un delito como el de asociación ilícita y conducir paradojalmente a desproteger bienes jurídicos de suyo importantes para la sociedad y el orden constitucional" (rol I.44I-2009). Con todo, en sentencia anterior, rol 739-2007, el H. Tribunal rechazó la misma alegación de inconstitucionalidad argumentando que se trataría de un delito de "peligro concreto" y, por tanto, no se infringiría el principio de legalidad en tanto "dicha circunstancia (el peligro) debe ser acreditada”.

30 Se ha discutido la inconstitucionalidad de este artículo por establecer supuestamente una ley penal en blanco, infringiéndose el mandato de determinación. Sin embargo, el H. Tribunal Constitucional, en resolución dictada el 23 de diciembre de 20I4, ha rechazado esta argumentación, entendiendo que "la jurisprudencia de esta magistratura ha sostenido que el mandato de la Constitución es compatible con la existencia de una ley penal en blanco impropia, que es aquella cuyo complemento se encuentra en una disposición normativa de igual jerarquía...”, agregando que, "el artículo 292 del código penal contiene el núcleo de la conducta punible, que no es otro que asociarse $u$ organizarse para perpetrar delitos, disposición que es complementada por el artículo 293 del mismo código, que fija la pena aplicable de acuerdo con

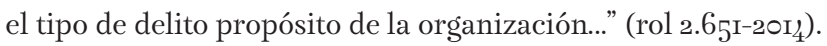


manifiestamente a la palabra "partida" un sentido y alcance diverso del que entendió el Sr. Gandarillas en la célebre sesión $157^{\mathrm{a}}$. Gramaticalmente, una de las acepciones de la suprimida palabra refiere que se trata de un «conjunto poco numeroso de gente armada, con organización militar u otra semejante» ${ }^{31}$. Al ser concordada con los artículos posteriores del modelo belga, la acepción adquiere todo el significado que justamente la supresión del comisionado quiso resaltar: el artículo inmediatamente siguiente del Código Penal belga contenía una alusión a los "jefes de esa partida" (artículo 323); luego, el modelo hacía sinónimos la palabra "partida” con "divisiones" (artículo 324); y aún más claro, el artículo 326 del modelo se refería a los "comandantes en jefe o de división".

En consecuencia, la pretendida transitoriedad o temporalidad que quiso ver el comisionado Sr. Gandarillas en el empleo de la palabra "partida" no era tal, y mucho menos podía confundirse con una conspiración para delinquir. Antes bien, todo el articulado descansaba en la existencia de un delito cuyos presupuestos típicos objetivos suponen la existencia de varias personas, una estructura y jerarquía funcional y normativa, cierta permanencia en el tiempo y una finalidad delictiva determinada por un programa o agenda criminal. Así las cosas, la palabra más bien estaba destinada a precisar y dotar de contenido estructural al delito, y no como pensó el comisionado Sr. Gandarillas, a restarle densidad, estabilidad y permanencia.

No obstante ello, la conocida supresión tuvo la importancia de incorporar a las escuetas actas de la Comisión Redactora el claro sentido y alcance del injusto típico. De no ser por esta intervención, la opinión doctrinal y jurisprudencial sí habría tenido el valor de "establecer”, al menos en este aspecto, la configuración de los elementos típicos del delito ${ }^{32}$.

5.2. Los artículos 292 y 293 del Código Penal y la cuestión sobre la finalidad amplia o limitada del programa criminal de la asociación

En la sesión $62^{a}$, de 16 de octubre de 1871, se amplió el catálogo de intereses afectados por la asociación ilícita a que se refiere el artículo 292 del Código Penal, en relación a lo que

31 Consultado en Real Academia Española (RAE) <<https://dle.rae.es/2id=SoXqZnr $>>$ [consulta realizada el 30 de mayo de 20 I9].

32 Resulta curioso advertir que toda esta argumentación del comisionado Sr. Gandarillas, se habría generado por una circunstancia más bien fortuita. Consta en las actas de la Comisión Redactora que en la sesión $62^{\mathrm{a}}$, de i6 de octubre de i87i, en la que se adoptó la decisión de tomar como modelos del delito los artículos $3^{22}$ a 326 del Código Penal belga, no asistió este comisionado, quedando aprobados los preceptos sin abrirse mayor debate al respecto. Sólo en la etapa de revisión, en particular en la sesión $\mathrm{I}_{57^{\mathrm{a}}}$, el Sr. Gandarillas se mostró particularmente inquieto, efectuando una serie de precisiones que han permitido hasta el día de hoy mantener un sucinto pero provechoso registro histórico-legislativo. 
disponía el modelo belga. Así, de la redacción original que se refería únicamente a "las personas o las propiedades", se pasó al "orden social, contra las buenas costumbres, las personas o las propiedades".

Esta mención literal de intereses afectados ha llevado a algunos a sostener que los delitos que conforman el programa criminal sólo estarían acotados a aquellos que atentan precisamente contra tales objetivos:

Deben restringirse a aquellos delitos que se refieran a la idea de atentado contra el orden social, las buenas costumbres, las propiedades y las personas. Ha de tenerse en cuenta que esa restricción resulta a lo menos compleja en el caso de los dos primeros supuestos, dado que el concepto de orden social no puede ser interpretado de manera tan amplia que abarque cualquier delito, sino aquellos que traten de alteraciones de la denominada paz pública y aquellos que en el marco de los delitos contra la autodeterminación sexual puedan calificarse de los atentados contra las buenas costumbres ${ }^{33}$.

La argumentación anterior no se condice con el examen de las actas de la Comisión Redactora del Código Penal, que dan cuenta de una breve pero fructífera controversia relativa justamente a determinar el alcance que tenían los artículos 292 y 293 en relación a los delitos perseguidos por la asociación. Habiéndose examinado previamente la redacción histórica del artículo 292 del Código Penal, resta hacer otro tanto con el actual artículo 293, recogido del precepto 323 del modelo belga, que disponía lo siguiente:

Si la asociación ha tenido por objeto la perpetración de crímenes que traen aparejada la pena de muerte o de trabajos forzados, los provocadores de esa asociación, los jefes de esa partida i los que hubieren ejercido en ella un mando cualquiera, serán castigados con la reclusion.

Serán castigados con una prision de dos a cinco años, si la asociación ha sido formada para cometer otros crímenes; y con una prisión de seis meses a tres años, si la asociación ha sido formada para cometer delitos ${ }^{34}$.

La Comisión Redactora efectuó algunos cambios, que se mantienen vigentes en la actualidad:

Si la asociacion ha tenido por objeto la perpetración de crímenes, los jefes, los que hubieren ejercido mando en ella i sus provocadores, sufrirán la pena de presidio mayor en cualquiera de sus grados.

33 Medina, "El injusto de la asociación ilícita", ${ }_{4}^{8} 82-{ }_{4} 83$.

34 Verdugo, Código Penal..., 64 o. 
Cuando la asociacion ha tenido por objeto la perpetracion de simples delitos, la pena será de presidio menor en cualquiera de sus grados para los individuos comprendidos en el acápite anterior.

Con independencia de otras diferencias en la redacción de ambos artículos, en lo que dice relación con la finalidad delictiva de la asociación o programa criminal, únicamente se diferenció si el fin de la misma era la comisión de crímenes o simples delitos, sin la subdistinción que efectuaba el modelo belga en atención a la gravedad de la pena aparejada al crimen. Luego, al menos preliminarmente, no se aprecia motivo alguno para suponer que tales crímenes o simples delitos estarían limitados por los intereses que menciona el artículo 292. No existe referencia o indicación alguna en tal sentido. Únicamente, en lo relativo a las faltas, se las excluyó expresamente como objetivos de la agenda delictiva ${ }^{35}$.

Por otra parte, al analizar los cambios en la redacción final del artículo 292 del Código Penal, no se advierte en las actas de la sesión $62^{\mathrm{a}}$, de 16 de octubre de 1871, los motivos que tuvo en vista la Comisión para incorporar, además de las personas o las propiedades, al orden social y a las buenas costumbres. Luego, hasta este punto, no existe antecedente alguno que permita colegir que los miembros de la Comisión Redactora hayan estado especialmente interesados o preocupados por "ampliar" el catálogo de intereses afectados por la agenda criminal, supuestamente limitados desde su origen.

Con todo, el antecedente más claro para la resolución de esta problemática se encuentra en la etapa de revisión de los artículos, en particular, en la sesión 157 ${ }^{\text {a }}$, de 18 de junio de 1873. El inquieto comisionado don José Antonio Gandarillas planteó la siguiente observación:

Refiriéndose a la disposición de los dos artículos anteriores (actuales 292 y 293), hizo notar que en ellos solo se impone pena a las asociaciones destinadas a cometer delitos, mientras que en el art. 295 (actual 292) se han declarado ilícitas todas aquellas que ataquen a las buenas costumbres o al orden social, como seria por ejemplo los que predicaran la disolución del matrimonio o de la familia, el desconocimiento del derecho de propiedad, etc., todo lo cual no

35 Cuestión esta última que nos permite excluir como objeto de protección del delito al "recto ejercicio del derecho de asociación”. De otra forma, no se advierte cómo un programa criminal integrado por faltas no podría afectar igualmente dicho derecho constitucional. Si sólo se ha reservado en la agenda delictiva la comisión de crímenes o simples delitos, entonces, se aviene más la idea del orden y seguridad pública como objetos primarios de protección, que resultan "lesionados" al quedar los asociados organizados jerárquica, funcional y normativamente. La "hegemonía del poder estatal" o "autotutela del Estado" difícilmente puede ser objeto de protección por el tipo penal básico del Código Penal, sin perjuicio de las conclusiones que puedan obtenerse del análisis de la normativa referida a las organizaciones delictivas en la Ley i9.927, de seguridad del Estado, y en la Ley I8.3푼, que determina las conductas terroristas y su penalidad. 
tiene asignada pena en este Código, i por consiguiente no debe reputarse delito. De esta manera habría muchas asociaciones ilícitas i punibles, segun el art. 295, que sin embargo no recibirán castigo alguno ${ }^{36}$. A esto contestó el comisionado don Alejandro Reyes que los actos o principios citados por el señor Gandarillas importan verdaderos ataques contra los derechos reconocidos i amparados por la lei, de modo que siempre podrá descubrirse i penarse en ellos un delito, lo que evitará el inconveniente indicado si esos actos o principios por ningun título merecieran ser considerados como criminales, no seria justo tampoco perseguir a las asociaciones en cuyo seno se propalan o admiten ${ }^{37}$.

Esta breve discusión nos permite aclarar el sentido y alcance que quiso imprimir la Comisión Redactora a la mención de intereses del artículo 292 del Código Penal, que no sería otro que una enunciación ejemplar de los eventuales objetos de afectación de la organización delictiva. De otro modo, no se explica la referencia amplia que hizo el comisionado Sr. Reyes a los «derechos reconocidos i amparados por la lei, de modo que siempre podrá descubrirse i penarse en ellos un delito». Esto, sumado al razonable argumento relativo a la atipicidad de la asociación si los fines perseguidos «por ningun título merecieran ser considerados como criminales», es decir, si no están sancionados de alguna forma -como crimen o simple delito- en la legislación penal.

En consecuencia, la enunciación de intereses del artículo 292 del Código Penal es meramente ilustrativa, pues siempre y cuando en los fines de la asociación se pueda descubrir y penar un delito (salvo las faltas), entonces, será aplicable el tipo penal en cuestión, en la medida que se reúnan los otros presupuestos "precisados" por la doctrina y la jurisprudencia. En este sentido se pronuncia Grisolía, para quien los delitos perseguidos por la asociación criminal han de estar particularmente descritos en el Código Penal o en leyes especiales, entre otras razones, porque la penalidad del ilícito está dada en función de que se persiga la comisión de un crimen o simple delito, citando al efecto la opinión del comisionado don Alejandro Reyes en la sesión 157, de 18 de octubre de $1873^{38}$.

\subsection{Los artículos 292 y 293 del Código Penal y el problema relativo a la cantidad mínima de miembros de la asociación ilícita}

A propósito de las modificaciones introducidas por la Comisión Redactora al artículo 293

36 Rivacoba, Código Penal..., 529.

37 Rivacoba, Código Penal..., 529.

38 Grisolía, "El delito de asociación ilícita", 84. Por su parte, Sebastián Soler sostiene que basta que "los hechos propuestos deben constituir delitos en la acepción técnica del término" (Sebastián Soler, Derecho Penal Argentino, Tomo II, actualizado por Guillermo Fierro (Buenos Aires: Tipográfica Editora Argentina, 1992), 606. 
del Código Penal, se generó un debate en la sesión 58 , de $1^{\circ}$ de septiembre de 1871, «entre los señores Reyes, Fábres y Gandarillas, sobre el alcance que debia darse al castigo de las sociedades ilícitas y secretas. Se resolvió considerar esta cuestion mas detenidamente cuando se discuta en particular el proyecto» ${ }^{39}$. Sin embargo, la penalidad se mantuvo tal cual se acordó en la sesión 62, de 16 de octubre de 1871.

Este inconcluso debate se relaciona indirectamente con un problema que ha sido más bien debatido a nivel doctrinal ${ }^{40}$, referido al mínimo de intervinientes necesarios para que exista una asociación ilícita. En concreto, de lo que se trata es de justificar si al menos dos personas son suficientes para configurar una organización delictiva.

En el Código Penal español del año 1848, modificado en 1850, se decidió sancionar el delito de sociedades secretas en forma separada a las asociaciones ilícitas, siendo estas últimas las asociaciones de "más de veinte miembros" que se reunían periódicamente para tratar asuntos religiosos, literarios o de otra clase, en cuya formación no hubiere mediado el consentimiento de la autoridad pública o no se observaren las condiciones que ésta hubiere fijado ${ }^{21}$. Pues bien, como los artículos 322 y 323 del modelo belga no contenían mención alguna al número de miembros mínimos exigidos por el tipo penal, sólo es posible concluir que la referencia de la Comisión Redactora a las sociedades secretas e ilícitas es en atención al modelo español de $1848^{42}$. Y precisamente, no obstante esta referencia a un número mínimo de miembros, la opción legislativa se orientó en el mismo sentido que el modelo belga, sin hacer exigencias de esta clase.

Sin embargo, el debate no ha estado exento de polémica. La doctrina más antigua se ha inclinado por no acotar la figura a un número mínimo de miembros, sosteniendo que «nuestro Código ha prescindido del número de los asociados i ha exijido sólo que constituyan un cuerpo organizado, con sus jefes y reglas propias, para quedar comprendidos en los preceptos de este párrafo»³ ${ }^{4}$. En el mismo sentido, Guzmán Dálbora ha argumentado

39 Rivacoba, Código Penal..., 36 I.

40 Jurisprudencialmente el asunto ha sido resuelto más bien de modo uniforme. Al respecto, cf. sentencias de la Excma. Corte Suprema rol 5·576-2007, 7.712-2008, 2.596-2009, 2.747-2009, 37.96520I5, 32.695-2018, todas las cuales refieren que la asociación u organización delictiva comprende todos los supuestos en que dos o más personas elaboran en común un proyecto delictivo.

41 Antonio García-Pablos, Asociaciones Ilícitas en el Código Penal (Barcelona: Antoni Bosch Editor S.A., 1978$), 25$ y ss.

42 El Código Penal español de i870, en sus artículos r98 y siguientes, no establecía un número mínimo de miembros para configurar la asociación ilícita.

43 Pedro Fernández, Código Penal de la República de Chile: Esplicado i concordado, Tomo II, Segunda Edición, (Santiago: Ediciones Imprenta, Litografía y Encuadernación Barcelona, 1899), 43. 
que «una asociación consigo mismo es una idea aberrante incluso a título de metáfora; antes bien, ella exige, por lo menos, dos individuos que con sus contribuciones parciales conjuguen un verbo, asociarse, que demanda la distribución de funciones $»^{44}$.

Pese a lo expuesto, algunos autores han denunciado la insuficiencia de dos personas para configurar la organización delictiva ${ }^{45}$. Así, para Grisolía «no hay duda que desde el punto de vista subjetivo es necesario que la manifestación de voluntad de los asociados sea percibida por los restantes para lograr el acuerdo y deben existir tantas manifestaciones de voluntad como personas. Ahora, es difícil pensar que este acuerdo se lleve a cabo entre solamente dos personas sin que esta hipótesis se confunda con una o más conspiraciones múltiples. Será necesario, entonces, que la asociación la integren, a lo menos, tres personas como señalan los códigos italiano y argentino» ${ }^{46}$. En el mismo sentido, Muñoz Conde ha afirmado que «En principio bastaría con dos, pero creo que del sentido originario de la expresión puede deducirse que son necesarias por lo menos tres personas para poder hablar de asociación $»^{47}$. Otro tanto argumenta Mañalich, para quien «Esto se sigue, como conclusión a fortiori, una vez que se acepta que ya para la existencia de una banda o cuadrilla criminal son necesarias tres personas $\gg^{48}$.

Conforme a los antecedentes contenidos en las actas de la Comisión Redactora, parece forzoso concluir -sin apartarse del tipo penal- que el delito de asociación ilícita se configura con al menos la intervención de dos miembros. No fue objeto de preocupación de los comisionados establecer un mínimo en tal sentido; tampoco se aviene con alguna exigencia histórica derivada del concepto de bandas o cuadrillas que empleaban otros códigos foráneos. De hecho, el Código Penal español de 1822, exigía al menos la intervención de

44 Guzmán Dálbora, "Objeto Jurídico”, 62. En similar sentido, Gustavo Labatut, Derecho penal, Tomo II, actualizada por Julio Zenteno, 9 a edición (Santiago: Editorial Jurídica, Julio 2006), Iog; Raimundo Del Río, para quien el número de asociados puede ser cualquiera superior a uno. Cf. Raimundo Del Río, Derecho Penal, Tomo III (Santiago: Ed. Nascimento, I935), 249.

45 Al respecto, el Tribunal de Juicio Oral en Lo Penal de Colina (RIT 7-2009; ingreso No ${ }_{2045^{-2009}}$ de la Corte de Apelaciones de Santiago que rechazó la nulidad interpuesta por la defensa), en sentencia de fecha 30 de junio de 2009 , argumenta que es necesaria "la concurrencia de un determinado número de personas, que pueden ser dos, pero lo normal es que por la complejidad de estas estructuras superen a tres" (considerando undécimo).

46 Grisolía, "El delito de asociación", 80.

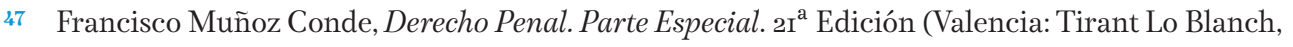
2OI7), 7II-7I2.

48 Mañalich, "Organización delictiva”, 295, pie de página n ${ }^{\circ} 5^{8}$. 
cuatro personas para sancionar a título de "cuadrilla", sin que haya sido observada esta exigencia por la Comisión Redactora ${ }^{29}$.

A mayor abundamiento, tratándose de tipos penales que simplemente presentan esquemas de conducta cuyos modos de realización no son uniformes, no parece aconsejable determinar a priori la imposibilidad de configurar una asociación ilícita formada únicamente por dos personas. Por lo demás, si se entiende la "perpetración" -fórmula verbal utilizada por el artículo 293- de crímenes y simples delitos materia del programa criminal en un sentido amplio -asociación formada "para perpetrar" o "para que se perpetren" crímenes o simples delitos-, deberían considerarse hipótesis tales como inducciones, provocaciones y complicidad ${ }^{50}$. Ciertamente, bajo estas amplias modalidades de propósitos criminales, sí sería concebible una estructura antijurídica de dos personas.

\section{5·. El artículo 294 del Código Penal y el problema del concurso de delitos}

Este artículo, según se ha señalado, no figuraba como norma originaria de nuestro Código Penal ni del modelo belga de 1867. Su incorporación se debe al artículo $1^{\circ}, \mathrm{N}^{\mathrm{o}} 3$, del Decreto Ley No 2.621 de 1979. Más adelante, a través de la Ley Nº 20.393, que estableció la responsabilidad penal de las personas jurídicas, se agregó un inciso segundo ${ }^{51}$, quedando redactada la norma de la siguiente forma:

Las penas de los artículos 293 y 294 se impondrán sin perjuicio de las que correspondan, por los crímenes o simples delitos cometidos con motivo u ocasión de tales actividades.

Cuando la asociación se hubiere formado a través de una persona jurídica, se impondrá además, como consecuencia accesoria de la pena impuesta a los responsables individuales, la disolución o cancelación de la personalidad jurídica.

Conforme al criterio general en doctrina y jurisprudencia, el inciso primero de este artículo regula expresamente un "concurso real" entre las penas de los artículos 293 y 294, esta-

49 El Código Penal del año i822, sancionaba las cuadrillas en el Capítulo VII, "De las cuadrillas de malhechores, y de los que roban caudales públicos, ó interceptan correos, ó hacen daños en bienes ó efectos pertenecientes al Estado ó al comun de los pueblos", artículo 338: "Es cuadrilla de malhechores toda reunión o asociación de cuatro o más personas mancomunadas para cometer juntas ó separadamente, pero de comun acuerdo, algun delito ó delitos contra las personas ó contra las propiedades, sean públicas ó particulares”. Asimismo, castigaba la creación de hermandades, cofradías u otras corporaciones fundadas o formadas sin consentimiento y licencia del gobierno. Al respecto, cfr., Grisolía, "El delito de asociación”, 79.

50 Antonio García-Pablos, Asociaciones Ilícitas..., 277. En el mismo sentido Juan Bustos, Manual de Derecho Penal Parte Especial, Segunda edición (Barcelona: Ed. Ariel, I991), 329.

51 Relación con los artículos $8^{\circ}$ y ss., de la Ley $\mathrm{N}^{0}{ }_{20} 0.393$. 
blecidas para la asociación ilícita, $\mathrm{y}$ «los crímenes o simples delitos cometidos con motivo u ocasión de tales actividades». En este sentido, Grisolía entendía que la introducción de esta regla reafirmó «por vía de la interpretación auténtica la necesaria concurrencia que se produce entre el delito formal del artículo 292 y aquellos crímenes o simples delitos que la banda actúe conforme a su plan criminal $\gg^{52}$, estando contenida la regla de penalidad en el artículo 74 del Código punitivo.

Este asunto, incluso, ha sido objeto de pronunciamiento por el Tribunal Constitucional, en virtud de un requerimiento de inaplicabilidad que impugnó la constitucionalidad de los artículos 292 y 293 del Código Penal (sin controvertir, curiosamente, el artículo 294 bis), denunciando que la sanción por el delito de asociación ilícita en forma separada de los delitos del programa criminal infringía el artículo $19 \mathrm{~N}^{0} 3$ de la Constitución Política, en concreto los principios de non bis in ídem y el de proporcionalidad de las penas. Se rechazó con costas el requerimiento en este punto, al considerar el Tribunal que «no se pena, pues, dos veces la misma infracción, sino que una sola vez infracciones distintas ${ }^{53}$.

Al revisar los motivos y fundamentos del Decreto Ley N ${ }^{\circ} 2.621$ de 1979, para introducir una serie de severas modificaciones al articulado original del delito de asociación ilícita ${ }^{54}$, se advierte que el objetivo concreto de este artículo 294 bis fue establecer un concurso real entre la organización delictiva y su programa o agenda criminal. A modo ilustrativo, el Boletín de Prensa número 147, de 27 de abril de 1979, que se transcribe en lo pertinente, estimó insuficiente la regulación que ofrecía a esa época el Código Penal:

La realidad ha demostrado, sin embargo, que la cobardía moral de quienes se asocian ilícitamente, los lleva a encubrir sus siniestros objetivos bajo apariencias que en oportunidades hacen parecer a sus organizaciones como entidades hasta de bien público. En consecuencia, la figura penal en vigor es insuficiente [...] Habrán de cuidarse pues las asociaciones de toda índole de admitir entre sus miembros

52 Grisolía, "El delito de asociación”, 86.

53 Sentencia rol I.441-2009. En el mismo sentido, haciendo aplicación de esta fórmula concursal sin argumentarlo en el fallo, imponiendo penas separadas para la asociación ilícita y los delitos fines, cf. a modo ilustrativo las sentencias de la Iltma. Corte de Apelaciones de Santiago en el rol 6.9052007, $43^{8-20 I 5}$; sentencias de la Excma. Corte Suprema rol 2.747-2009, 8.547.20I5, I9.676-2016.

54 Esta severidad se manifiesta en el inciso segundo introducido por el Decreto Ley 2.62i, al artículo 292 del Código Penal: "Se presumirá que la asociación ha tenido alguno de los objetos que se indican en el inciso anterior, cuando uno o más de sus miembros ha ejecutado algún acto que constituya un atentado contra el orden social, las buenas costumbres, las personas o las propiedades". Para Grisolía, "El delito de asociación ilícita", 79, esta presunción constituía un "verdadero engendro legal", que finalmente fue derogado por el artículo ${ }_{4}^{\circ}$ de la Ley I9.047, de I 4 de febrero de I99I. 
a quienes ejecuten tales acciones ya que serán llevados todos sus integrantes a la justicia como asociaciones ilícitas; delito que existe por el sólo hecho de haberse organizado, a probar si son o no inocentes.

Sin embargo, la solución concursal anterior dista mucho de ser pacífica. Según Medina, habría que distinguir al menos tres situaciones para determinar si procede aplicar al caso concreto un concurso aparente de leyes (por absorción), un concurso real (artículo 74 del Código Penal) o un concurso ideal (artículo 75 del Código Penal) ${ }^{55}$. Por su parte, bajo un argumento que niega la existencia de un concurso aparente, reconociéndolo como "auténtico" concurso, calificado de ideal o real según se satisfagan o no los presupuestos de una "unidad de hecho", Mañalich sostiene que «Bajo la representación legislativa es inequívoco, entonces, que el injusto de la asociación ilícita es enteramente independiente del injusto de los eventuales hechos delictivos específicos cuya perpetración constituye el objeto de la asociación» ${ }^{56}$.

Parece ser este último el criterio acogido por la Excma. Corte Suprema en la sentencia pronunciada en el proceso rol 3.465-2005, que en definitiva absolvió por el delito de asociación ilícita para el tráfico de estupefacientes contenido en el antiguo artículo 22 de la Ley 19.366, dejando sin aplicación lo dispuesto en el artículo 74 del Código Penal ${ }^{57}$. El considerando $9^{\circ}$ de esta sentencia razonó de la siguiente forma:

Que la situación producida en autos es la de la pluralidad de conductas y que corresponden a una pluralidad de delitos, un típico concurso real, pero por la influencia de la normativa penal establecida para la determinación de la penalidad en el Código Penal, en los casos de concurso real y concurso ideal, no obstante que se trata de dos delitos claramente tipificados, para efectos de su penalidad, se considerarán los delitos de este proceso en concurso ideal impropio, esto es, uno de los delitos, el de asociación ilícita, ha sido el medio necesario para cometer el delito de tráfico de sustancias estupefacientes, produciéndose uno de los casos de excepción al artículo 74 del Código Penal que contempla el artículo 75 del mismo cuerpo legal, siendo la conexión de uno y otro la circunstancia o hecho que le da físicamente la condición de delitos en concurso ideal.

No obstante lo anterior, considerando el injusto propio de la organización delictiva, y, por tanto, la autonomía en relación a aquellos delitos que conforman su programa criminal,

55 Medina, "El injusto de la asociación ilícita", 5०2-5०3.

56 Mañalich, "Organización delictiva”, 294.

57 El tipo penal del artículo 22 de la Ley I9.366, bajo una hipótesis parecida a la de los artículos 292 y 293 del Código Penal, disponía lo siguiente: "Los que se asociaren u organizaren con el objeto de cometer alguno de los delitos contemplados en esta ley, serán sancionados, por este solo hecho [...]”. 
sumado a los antecedentes proporcionados por el elemento histórico, no resulta plausible proclamar una fórmula concursal diversa por la vía de un concurso ideal o aparente. Los delitos cometidos en virtud de la agenda criminal de la asociación han de ser sancionados de manera independiente ${ }^{58}$, de lo contrario siempre los "delitos fines" serán un medio para concretar el propósito criminal de los asociados y, por tanto, en los términos de la Corte Suprema, en todos los casos será posible advertir una "conexión" entre la estructura criminal y su programa delictual. Entendiendo que el "objeto social" de la asociación es su meta criminal, que trasciende a los miembros individualmente considerados, y que, por tanto, es expresión de la voluntad corporativa ${ }^{59}$, no habría sino que admitir en la mayoría de los casos la concurrencia, al menos, de un concurso ideal; solución insatisfactoria que, no obstante, es refutable únicamente respecto de la asociación ilícita común de los artículos 292 y siguientes del Código Penal, no así de aquellas estructuras antijurídicas que se regulan en leyes especiales y que, en consecuencia, plantean una identidad de objetos de afectación, como sería el caso del artículo 16 de la Ley $20.000^{60}$.

\section{Conclusiones}

El delito de asociación ilícita de los artículos 292 y siguientes del Código Penal chileno reconoce como antecedente inmediato al Código Penal belga de 1863. Si bien buena parte del articulado fue adoptado casi en su literalidad de este modelo, se introdujeron algunas modificaciones tendientes a armonizar el lenguaje y mantener la coherencia con el resto del código.

De entre estas modificaciones destacan aquellas explicitadas en el seno de la Comisión Redactora por don José Antonio Gandarillas, que si bien no eran estrictamente necesarias, sí han sido provechosas para comprender el sentido y alcance del tipo penal, especialmente en su densidad estructural.

Los antecedentes histórico-legislativos referidos al artículo 292 del Código Penal permiten determinar claramente los presupuestos objetivos del injusto, esto es, la existencia de una

59 En este sentido Antonio García-Pablos, Asociaciones Ilícitas..., 24o; Sebastián Soler, Derecho Penal..., 605.

60 Para Guzmán Dálbora, “Objeto Jurídico”, 79, la normativa referida al tráfico ilícito de estupefacientes y sustancias psicotrópicas (la antigua normativa, que en la materia no reviste cambios sustanciales), "castiga apenas una 'conspiración' para cometer los delitos sobre estupefacientes, o sea, una 'resolución manifestada' que funciona como 'acto preparatorio' en punto a la producción y el tráfico indebido de dichas substancias". De esta forma, "el bien jurídico ofendido con las últimas conductas (la salud pública) (es) 'el mismo' que el que protege la peculiarísima asociación"; con lo que "se colige que la asociación criminal en comentario es de aplicación únicamente en el caso de que los delitos programados no se consumen”. 
asociación organizada jerárquica, funcional y normativamente con miras a un programa criminal. La íntima vinculación entre los términos "asociar" y "organizar" es relevante para entender correctamente el injusto.

Las actas de la Comisión Redactora y la legislación histórica de contexto permiten resolver el problema relativo a la cantidad mínima de miembros que debe tener la asociación delictiva y la finalidad amplia o limitada del programa o agenda criminal. En cuanto al mínimo de miembros, razones de texto e históricas permiten sostener que bastan dos personas para entender configurada la organización delictiva. Sobre la finalidad amplia o limitada, iguales motivos permiten afirmar que el artículo 292 del Código Penal sólo menciona por vía ejemplar ciertos intereses afectados por la asociación ilícita.

En materia concursal, el origen legislativo y político del artículo 294 bis del Código Penal permite explicar su objetivo excluyente de sancionar por la vía de "concurso real" la convergencia entre el delito de asociación ilícita y los delitos objeto del programa criminal. La posibilidad de establecer un concurso ideal sólo estaría dada en los casos concretos que tipifican ciertas leyes especiales, como por ejemplo la Ley 20.000, sobre tráfico ilícito de estupefacientes y sustancias sicotrópicas. 


\section{BIBLIOGRAFÍA}

- Andreucci Aguilera, Rodrigo. "Los conceptos de la Corte Suprema sobre interpretación de la ley a través de sus sentencias”, Nomos, $n^{0}$ I (2008): II-39.

- Bustos, Juan. Manual de Derecho Penal Parte Especial. Segunda edición, Barcelona: Ed. Ariel, I99I.

- Cury, Enrique. Derecho Penal Parte General. Santiago: Ediciones UC, 2009 .

- Del Río, Raimundo. Derecho Penal, Tomo III. Santiago: Ed. Nascimento, 1935 .

- Etcheberry, Alfredo. El Derecho Penal en la Jurisprudencia, Tomo III, Segunda Edición. Santiago: Ed. Jurídica de Chile, I987.

- Etcheberry, Alfredo. Derecho Penal Parte General, Tomo I, $3^{\mathrm{a}}$ Ed. Santiago: Editorial Jurídica de Chile, rg99.

- Fernández, Pedro. Código Penal de la República de Chile: Esplicado $i$ concordado, Tomo II, Segunda Edición. Santiago: Ediciones Imprenta, Litografía y Encuadernación Barcelona, I899.

- Fiandaca, Giovanni y Musco, Enzo. Derecho Penal, Parte General. Bogotá: Editorial Temis S.A., 2006.

- Fuensalida, Alejandro. Concordancias i comentarios del Código Penal Chileno, Tomo I., Lima: Imp. Comercial Calle del Huallaca N.I39, I883.

- García-Pablos, Antonio. Asociaciones Ilícitas en el Código Penal. Barcelona: Antoni Bosch Editor S.A., 1978.

- Garrido Montt, Mario. Derecho Penal Parte General, Tomo I, $2^{\mathrm{a}}$ Ed. Santiago: Editorial Jurídica de Chile, 2007.

- Grisolía, Francisco. "El delito de asociación ilícita", Revista Chilena

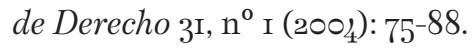


- Guzmán Dálbora, José. "Objeto Jurídico y Accidentes del Delito de Asociaciones Ilícitas”, Estudios y Defensas Penales. Santiago: Ed. Lexis Nexis, 2005 .

- Iñesta Pastor, Emilia. "El Código Penal Chileno de I874,. Revista Chilena de Historia del Derecho, $\mathrm{n}^{0}$ I9 (2003-2004): 293-328.

- Labatut, Gustavo. Derecho penal, Tomo II. $9^{\text {a }}$ Ed. actualizada por Julio Zenteno. Santiago: Editorial Jurídica, 2006.

- Luzón Peña, Diego. Lecciones de Derecho Penal Parte General, $3{ }^{\mathrm{a}}$ Ed. Valencia: Tirant Lo Blanch, 2016.

- Mañalich, Juan Pablo. "Organización delictiva. Bases para elaboración dogmática en el derecho penal chileno”. Revista Chilena de Derecho $3^{8} \mathrm{n}^{0} 2$ (20II): 279-310.

- Mac Iver, Luis. Derecho penal Chileno. Parte General. Tomo I. Santiago: Editorial Jurídica de Chile, I975.

- Matus, Jean Pierre. "La doctrina penal de la (fallida) recodificación chilena del siglo XX y principios del XXI", Polít.Crim. $5 \cdot$ n $^{\circ} 9$ (20I0): I $43-206$.

- Medina, Gonzalo. "El injusto de la asociación ilícita como problema de la estructura de afectación del bien jurídico". La Ciencia Penal en la Universidad de Chile, Facultad de Derecho de la Universidad de Chile, (20I3).

- Muñoz Conde, Francisco. Derecho Penal. Parte Especial. 21 ${ }^{\mathrm{a}}$ Edición. Valencia: Tirant Lo Blanch, 20I7.

- Novoa, Eduardo. Curso de Derecho Penal Chileno, Parte General, Tomo

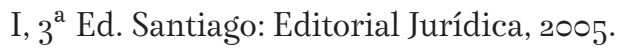

- Politoff, Sergio, Jean Pierre Matus y Cecilia Ramírez. Lecciones de Derecho Penal Chileno. Parte General. Santiago: Editorial Jurídica de Chile, 2004 .

- Rivacoba, Manuel de. Código Penal de la República de Chile y actas de las sesiones de la Comisión Redactora del Código Penal Chileno. Valparaíso: Editorial EDEVAL, 1974. 
- Rodríguez-Toubes, Joaquín. "El criterio histórico en la interpretación jurídica”. Dereito 22, no 599-632 (Noviembre, 20I3): 599-632.

- Roxin, Claus. Derecho Penal Parte General, Tomo I. Trad. $2^{\text {a }}$ Edición alemana. España: Editorial Civitas, 2008.

- Soler, Sebastián. Derecho Penal Argentino, Tomo I. Actualizado por Guillermo Fierro, ${ }^{2}{ }^{a}$ Ed. Buenos Aires: Tipográfica Editora Argentina, I992.

- Soler, Sebastián, Derecho Penal Argentino, Tomo II. Actualizado por Guillermo Fierro, $10^{a}$ Ed. Buenos Aires: Tipográfica Editora Argentina, I992.

- Verdugo, Mario. Código Penal: concordancias, antecedentes históricos, doctrina y jurisprudencia, Tomo II. Santiago: Editorial Jurídica EdiarConosur, 1986.

- Vidaurri, Manuel. "La interpretación de la Ley Penal". AA.VV. Liber Ad Honorem Sergio García Ramírez, Tomo I. Universidad Nacional Autónoma de México, Instituto de Investigaciones Jurídicas, Serie E; Varios, Núm 94, 1998, 73-75०.

- Von Savigny, Fiedrich Karl. Sistema del Derecho Romano Actual. Tomo Primero, $2^{\text {a }}$ Ed. Madrid: Centro Editorial de Góngora, $1839-1847$.

- Zavala, Manuel, José Ignacio Serrano y Prudencia Meiquia, trads. Código Penal Francés traducido. México, I866. 